\section{Lost and found}

\section{European funders are right to consider the career prospects of young scientists.}

$\mathrm{I}$ $\mathrm{t}$ is a century since the first génération perdue came of age. The phrase is attributed to US writer Gertrude Stein, who heard it as a casual insult aimed by a garage boss at a young French mechanic who was working - too slowly - on Stein's car. The term is now generally used to describe a group of people who are lost to society. So when European officials spoke at a conference session last week called 'The lost generation of European scientists', for many participants the name would have conjured up thoughts of an exodus of talented early-career researchers, who are fed up with the insecurity of short-term jobs and with dwindling opportunities in academia. And so it should have: in many disciplines, that issue is real, growing and serious. Young and early-career researchers need the problem to be taken seriously - and so does the rest of the scientific community. Figures are difficult to come by, but less than one-fifth of US postdocs secure a tenured research position, and the situation is even more competitive in Europe.

The 'lost generation' tag has another, more subtle meaning. Popularized by US writer Ernest Hemingway, it was used to describe the age group - Hemingway included - that had been left disoriented and confused by growing up amid the horrors and chaos of the First World War. Lost, not missing. The distinction is important. Careers outside academia are just as valuable and senior scientists must acknowledge this. Nevertheless, young researchers are too often led to believe that a non-academic career is inferior, so individual scientists who find they need to look elsewhere often feel let down, deceived and cynical.

Last week's event, held at the EuroScience Open Forum in Toulouse,

France, covered all of that ground. The session was well attended and was frank about the scale of the problem and the difficulty of finding solutions. This might indicate that European funders and policymakers are catching up with the United States, where the crisis of confidence and opportunity among young scientists - especially in biomedicine - has been widely debated for at least a decade. That would be good news. The bad news is that Europe's fragmented, variable national research bodies and strong university autonomy make it much easier to acknowledge the problem than to change the systems that cause it.

At the meeting, European Research Council president Jean-Pierre Bourguignon hinted at an obvious fix: increase funding for scientific research and create more permanent academic jobs. But that's a big

"Universities should track and provide data on how many academicjobs are available." ask, and one that would take time. A moreimmediate solution calls for more-specific and targeted changes. One is the creation of more full-time staff scientist positions, although such posts (with benefits such as pensions) raise institution costs.

As we have argued previously (Nature 550, 429; 2017), there is a pressing need for greater transparency about the likelihood of $\mathrm{PhD}$ students and postdocs following an academic career to the higher levels. A suggestion made at last week's session - and one that Nature endorses - is that universities and other institutions should track and provide data on how many academic jobs are available at each level, and list the destination of every scientist who moves on. The US National Academies has made an attempt at doing this for postdocs, and the European Science Foundation has tried to track the fate of Europe's PhD holders. Both are good models to follow.

Better information won't solve all the problems of all the 'lost' researchers, but it will at least provide them with a map as they decide on their next move. Those who supervise $\mathrm{PhD}$ students and postdocs must show them such a map, and take responsibility for preparing them for non-academic careers. What might look like a loss for academia can still be a great gain for society.

\section{Gone rogue}

\section{Officials and scientists need help to track down source of a worrying rise in CFC emissions.}

\footnotetext{
A fter three decades of being lauded as pioneers in successful environmental stewardship, officials who safeguard Earth's ozone layer are facing an unexpected crisis: how to identify and cut off a rogue new source of ozone-destroying chemicals (S. A. Montzka et al. Nature 557, 413-417; 2018). If not stopped, the emissions of CFC-11 might delay by several decades the healing of ozone holes that appear at high latitudes early each spring. As expected, the issue featured heavily at last week's meeting in Vienna of the Open-Ended Working Group (OEWG) of the Montreal Protocol, which protects the ozone layer. Since the protocol's launch in 1987, countries have curbed the use of ozone-depleting chemicals in refrigeration and other industrial processes.

Ahead of the meeting, media reports and an analysis by the Londonbased Environmental Investigation Agency - a non-governmental organization with observer status in the Montreal Protocol - used interviews with company executives and information contained in advertisements to suggest that foam-manufacturing companies in rural China are to blame. Chinese delegates in Vienna made it clear that they take the matter seriously and, by all accounts, the issue has gone up to the level of Chinese President Xi Jinping. But they remained extremely reluctant to concede any serious wrongdoings on the part of
}

Chinese companies, or government negligence in their oversight. This is understandable given that there is not yet definite evidence concerning the sources, quantity, duration or nature of the rogue emissions.

The suspicion that Chinese factories are the main - perhaps the sole - source of the damaging CFC-11 chemicals cannot be dismissed. But for now, increased vigilance must apply to the whole of South and East Asia. To pinpoint the source of the rogue emissions precisely, members of the Montreal Protocol's scientific assessment panel are working to analyse the most recent data from the region's atmospheric monitoring stations, including those of South Korea and Japan. Governments must make available, without delay, any data required for further analysis, and should also provide any other intelligence, such as that from commercial register entries, advertisements or customs, that could help to pin down any source of the emissions. The issue is a test of the strength and muscle of the Montreal Protocol regime, which must mobilize all the pieces - science, monitoring, verification and, possibly, sanctions. Already, four years have elapsed since scientists observed and reported the worrying CFC spike. What's needed now, besides enduring vigilance, is a rapid political and institutional effort.

There is no doubt that China has, over the past few years, stepped up its environmental efforts, including those tackling air pollution and greenhouse-gas emissions. If Chinese sources of CFC-11 production are confirmed, the government should engage its full enforcement capacity to stop it immediately. Ironically, the current crisis is an opportunity for China to demonstrate its emerging leadership in the enforcement of global environmental policies. If the Montreal Protocol survives this test, the most beneficial environmental pact the world has ever undertaken will surely emerge stronger than ever.. 